\title{
The first theropod tracks from the Middle Jurassic of Gansu, Northwest China: new and rare evidence of quadrupedal progression in theropod dinosaurs
}

\author{
Da-Qing Li ${ }^{*}$, Li-Da Xing ${ }^{2,3^{*}} \mathbb{D}$, Martin G. Lockley ${ }^{4}$, Anthony Romilio ${ }^{5}$, Jing-Tao Yang ${ }^{1}$ and Long-Feng Li ${ }^{1}$
}

\begin{abstract}
A new Middle Jurassic tracksite dominated by non-avian theropod footprints from the Wangjiashan Formation in Pingchuan District, Baojishan Basin, Gansu Province has yielded a unique trackway with four consecutive manus-pes sets. Only three previous examples, all Early Jurassic in age, of theropod trackways are known with convincing examples of manus tracks and in each case, only two tracks were recorded in association with pes tracks with metatarsal impressions and pelvic traces indicating crouching behavior. Thus, this is the first example of manus tracks registered while a theropod trackmaker was walking. This unique configuration is here designated as Grallator pingchuanensis ichnosp. nov. which shows the trackmaker forelimbs registering in a wide straddle gait, much wider than the pes trackway width. G. pingchuanensis confirms previous reports that theropods could occasionally register tridactyl, ectaxonic manus traces. In the case of the Pingchuan trackway, the short step indicates an animal moving at a slow speed, probably due to a soft substrate.
\end{abstract}

Keywords: Wangjiashan Formation, Grallatorid, Grallator, Theropods, Dinosaur tracks

\section{Introduction}

The discovery of dinosaur fossils in Gansu Province can be traced to 1930-1931 when the Sino-Swedish Expedition collected the first dinosaur material from the Mesozoic basins of western Gansu (Bohlin 1953). Only one possible Late Jurassic sauropod was found in the central part of Gansu before this study (Young 1948). This was eventually attributed to the sauropod genus Mamenchisaurus (Young and Zhao 1972). All other records from this region, including abundant skeletons and tracks, are from the Lower Cretaceous rock units.

In Gansu, the Yanguoxia tracksites yielded the most abundant and diverse track records, including well-preserved sauropod, ornithopod, dromaeosaur, theropod, pterosaur, and bird tracks and trackways (Zhang et al. 2006; Xing et al.

\footnotetext{
* Correspondence: daqingli@gsau.edu.cn; xinglida@cugb.edu.cn ${ }^{1}$ Institute of Vertebrate Paleontology and College of Life Science and Technology, Gansu Agricultural University, Lanzhou 730070, Gansu Province, China

${ }^{2}$ School of Earth Sciences and Resources, China University of Geosciences (Beijing), Beijing 100083, China

Full list of author information is available at the end of the article
}

2013a, 2016a, 2016b; Li et al. 2015). In the Honggu (Xing et al. 2014a), Zhongpu (Xing et al. 2014b, 2015), Guanshan (Xing et al. 2016a), and Changma (Xing et al. 2017) areas, some non-avian dinosaur and bird tracks were discovered.

The Institute of Vertebrate Paleontology, Gansu Agricultural University (IVPG) found an assemblage of tracks in the Baojishan Basin (Fig. 1) in year 2017. In the same fieldwork session, the IVPG also found a mamenchisaurid dinosaur, several large-sized theropod teeth and stegosaurian remains in the Baojishan Basin. In 2018, authors of this study investigated this tracksite again to make resin and 3D digit models. These tracks represent the only evidence of the Middle Jurassic smallto middle-sized theropod in Gansu, Northwest China.

\section{Geological setting}

The study area is in the northwestern Baojishan Basin, Pingchuan District of Baiyin City, Gansu Province. The Baojishan Basin is at the eastern end of Qilian Mountains. As a fault-bounded subsiding basin, it comprises a small part of the Hexi Corridor Basin which can be 


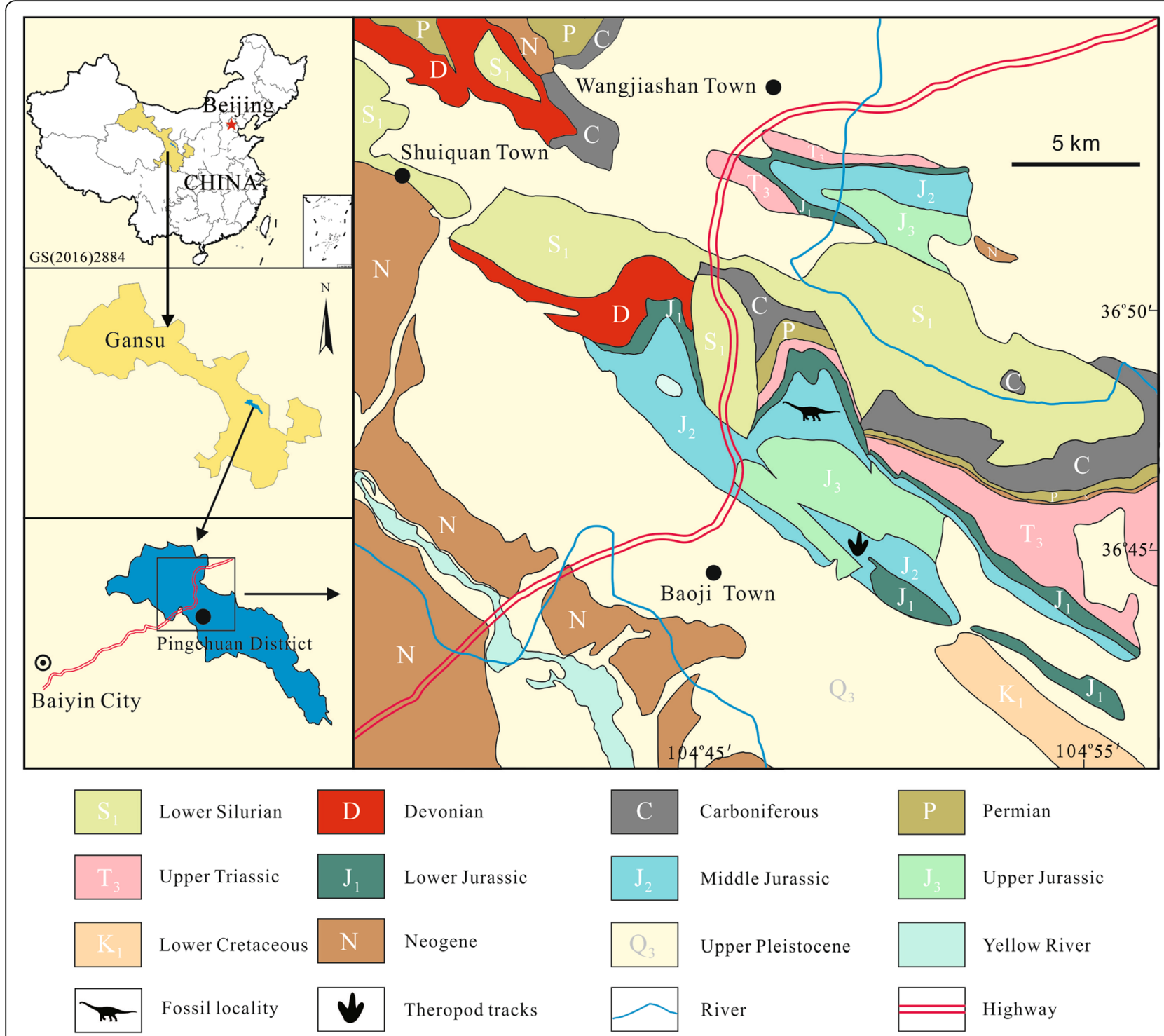

Fig. 1 Geographic and geologic maps showing the location of dinosaur tracks (Inset map of China is modified after State Buteau of Surveying and Mapping, GS(2016)2884). The study area is in the distributing range of the Jurassic strata

traced back to the Late Triassic and Jurassic. Its Middle Jurassic layers consist of two lithostratigraphic units, the Longfengshan Formation and the Wangjiashan Formation, in disconformable contact with the underlying Upper Triassic, and in conformable contact with the overlying Upper Jurassic (Fig. 2). The 607-m-thick Wangiiashan Formation was informally divided into two members based on differences in lithology and lithofacies (Li et al. 1982; Zhang 2009) (Fig. 2). The lower member is composed of straw-yellow sandstones $(477 \mathrm{~m}$ thick) which were deposited mainly in a lake deltaic setting with its succession characterized by straw-yellow color. The coarse sandstones at the bottom gradually change to finer grained units with red mudstones interbedded in the upper part of this member. The upper member is $113 \mathrm{~m}$ thick, and comprises gray to greenishgray siltstones and sandy mudstones, interbedded with thin beds of oil shale, mainly representing a lake environment.

Dinosaur fossils were recovered from sandstones in the upper part of the lower member (Fig. 2).

The oil shale member has yielded plant macrofossils, palynoflora and a lacustrine invertebrate assemblage, including conchostracans, charophytes, and bivalves. Based on this fossil material, the underlying straw-yellow sandstone member is thought to have been formed in the late Bathonian (Li et al. 1982; Du 1985; Zhang 2009). Similarities in the invertebrate and dinosaur assemblages (Li et al. 2011; Deng et al. 2017) imply some affinity between the Wangjiashan Formation in the Baojishan 


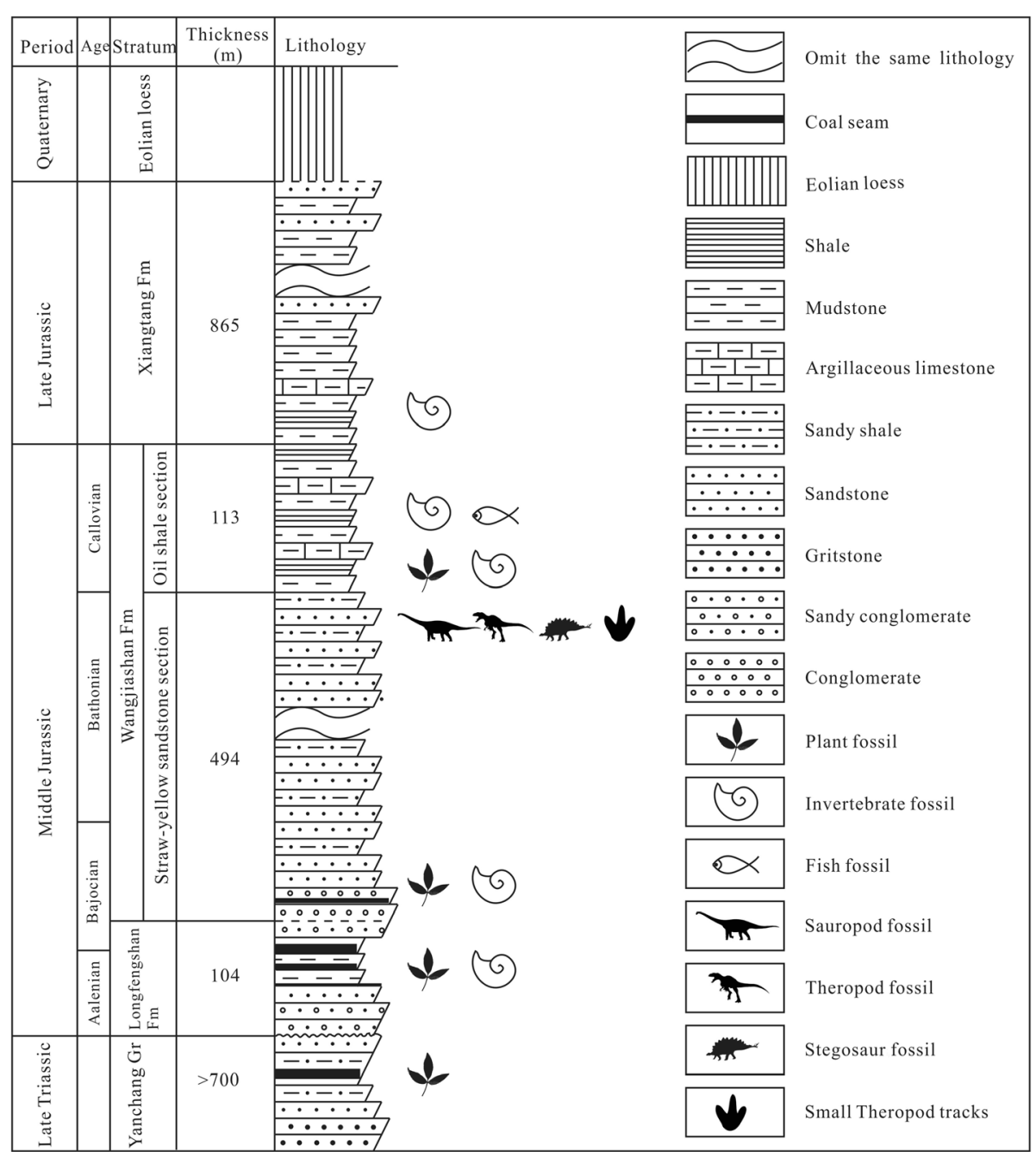

Fig. 2 Comprehensive stratigraphy and main fossil distribution of the Jurassic units in Pingchuan District of the Baojishan Basin, Gansu Province

Basin and the Lower Shaximiao Formation in the Sichuan Basin.

\section{Methods}

Tracks preserved as convex hyporeliefs (i.e., natural casts) were digitally photographed (115-164 images of each) from various angles using a Nikon D5 with a $24 \mathrm{~mm}$ lens. Photographic jpg images were added to Agisoft Photoscan Professional Edition (Version 1.2.6 build 203864 bit) to generate scale-corrected models following the procedure adapted from Xing et al. (2018). The 3D models were automatically aligned to the centre of the Cartesian coordinate system using R Studio (Version 1.1.453; Lallensack 2018). The surface topography was visualised as false-colour elevation, contour maps, and ambient occlusion images using Paraview (Version 5.0.0 64 bit; Ahrens et al. 2005) and CloudCompare (Version 2.6.1 64 bit; www.cloudcompare.org) software.
Olsen (1980), Weems (1992), and Lockley (2009) suggested that theropod tracks could be differentiated by their mesaxony $(\mathrm{M})$ : how far the tip of the central digit (III) is projects anteriorly beyond the tips of the medial (II) and lateral (IV) digits, defining an anterior triangle. In most assemblages, the L/W ratios of the anterior triangle (used as an index of mesaxony in this paper) and of the whole track show a positive correlation, that is, narrow tracks are normally stronger in mesaxony than wide tracks.

All measured tracks were numbered with the prefix PC, denoting Pingchuan, and numbered in the series PC-TI1-PCTI18 with TI indicating an isolated or individual theropod pes track. Manus tracks and other incomplete or undiagnostic tracks are not numbered. We measured the maximum pes track length $(M L)$, the maximum pes track width (MW), ML/MW ratios, divarication angles between digits II and IV, and the L/ $\mathrm{W}$ ratio of the anterior triangle as a measure of 
Table 1 Measurements of theropod tracks PC-TI1-PC-TI18 from Pingchuan tracksite, Gansu Province, Northwest China. PC-TI1PC-TI14 were from the Pingchuan assemblage A; PC-TI15 was from the Pingchuan assemblage B; PC-TI16-PC-TI18 were from the Pingchuan assemblage $C$

\begin{tabular}{|c|c|c|c|c|c|}
\hline Number & $\mathrm{ML}(\mathrm{cm})$ & $\mathrm{MW}(\mathrm{cm})$ & II-IV & $\mathrm{ML} / \mathrm{MW}$ & M \\
\hline$\overline{P C-T I 1}$ & 19.6 & 8.1 & $31^{\circ}$ & 2.4 & 0.76 \\
\hline PC-TI2 & 11.0 & 7.0 & $44^{\circ}$ & 1.6 & 0.32 \\
\hline PC-TI3 & 12.6 & 8.2 & $46^{\circ}$ & 1.5 & 0.43 \\
\hline PC-T14 & 11.0 & 7.4 & $55^{\circ}$ & 1.5 & 0.51 \\
\hline PC-TI5 & 17.1 & 10.1 & $44^{\circ}$ & 1.7 & 0.50 \\
\hline PC-T16 & 11.4 & 13.8 & $104^{\circ}$ & 0.8 & 0.40 \\
\hline PC-TI7 & 12.9 & 9.0 & $57^{\circ}$ & 1.4 & 0.55 \\
\hline PC-T18 & 8.9 & 12.1 & $90^{\circ}$ & 0.7 & 0.28 \\
\hline PC-TI9 & 17.0 & 8.5 & $35^{\circ}$ & 2.0 & 0.51 \\
\hline PC-TI10 & 12.2 & 6.7 & $42^{\circ}$ & 1.8 & 0.56 \\
\hline PC-TI11 & 16.3 & 8.2 & $40^{\circ}$ & 2.0 & 0.69 \\
\hline PC-TI12 & 11.5 & 6.5 & $38^{\circ}$ & 1.8 & 0.42 \\
\hline PC-TI13 & 14.1 & 6.6 & $37^{\circ}$ & 2.1 & 0.73 \\
\hline PC-TI14 & 14.5 & 10.5 & $60^{\circ}$ & 1.4 & 0.52 \\
\hline PC-TI15 & 12.0 & 8.5 & $53^{\circ}$ & 1.4 & 0.42 \\
\hline PC-TI16 & $>8.8$ & 7.7 & - & - & 0.54 \\
\hline PC-TI17 & $>8.3$ & 7.9 & - & - & 0.39 \\
\hline PC-TI18 & $>6.2$ & 6.5 & - & - & 0.43 \\
\hline
\end{tabular}

Notes: $M L$ Maximum pes track length, $M W$ Maximum pes track width (measured as the distance between the tips of digits II and IV), II-IV Angle between digits II and IV, M Mesaxony

mesaxony $(\mathrm{M})$ as defined above (Table 1 ). The size, morphology and position of manus tracks are described in the following sections.

\section{Descriptions of dinosaur tracks}

Dinosaur tracks from Pingchuan tracksite were visible on bedding planes in three areas denoted here as assemblages $\mathrm{A}, \mathrm{B}$, and $\mathrm{C}$ covering the surface of 3.5 $\mathrm{m}^{2}, 0.27 \mathrm{~m}^{2}$ and $0.34 \mathrm{~m}^{2}$ respectively (Figs. $3,4,5,6$ ). Assemblages $\mathrm{A}, \mathrm{B}$, and $\mathrm{C}$ were located in different layers. $\mathrm{A}$ is in the relatively highest layer, $\mathrm{B}$ is about $30 \mathrm{~cm}$ below $A$, and $C$ is the lowest, about $90 \mathrm{~cm}$ below A. All tracks were preserved in fine sandstones. Assemblages A and B yield many microbially induced sedimentary wrinkle structures and distinct mud cracks. Assemblage $\mathrm{C}$ has a lot of scratch marks parallel to the tracks.

Assemblage A has at least 37 tracks, most of which are oriented to the northwest while a minority point in the opposite direction, to the southeast. Quite a few tracks overlap. No clearly distinguishable trackway has been found. Measured tracks including PC-TI1-PC-TI14 are relatively well-preserved. These tracks can be divided into two types. Type A represents classic Grallator-like tridactyl theropod tracks, ranging from $11.0 \mathrm{~cm}$ to $19.6 \mathrm{~cm}$ in length and 1.4 to 2.4 in the $\mathrm{L} / \mathrm{W}$ ratio. The divarication angles between digits II and IV range between $31^{\circ}$ and $60^{\circ}$. The L/W ratios of the anterior triangle (mesaxony) are 0.32 to 0.76 . Some footprints, such as PC-TI1 and PC-TI11, have elongated heels which are likely to be traces of the metatarsal-phalangeal pads. The best preserved track is PC-TI3, with a length of $12.6 \mathrm{~cm}$, a width of $8.2 \mathrm{~cm}$, a L/W ratio of 1.5, a divarication angle between digits II and IV of $46^{\circ}$, and a mesaxony measure of 0.43 . Type $B$ represents very wide tridactyl tracks and includes PC-TI6 and PC-TI8. For PC-TI6, the length is $12.1 \mathrm{~cm}$, the $\mathrm{L} / \mathrm{W}$ ratio is 0.8 , the divarication angles range between digits II and IV is $104^{\circ}$, and the $\mathrm{L} / \mathrm{W}$ ratio of the anterior triangle (mesaxony) is 0.40 . For PC-TI8, the length is $13.8 \mathrm{~cm}$, the $\mathrm{L} / \mathrm{W}$ ratio is 0.7 , the divarication angles range between digits II and IV is $90^{\circ}$, and the mesaxony is 0.28 . Type B tracks are poorly preserved with unclear digit pads, and probably reflect extramorphological expressions of Type A tracks.

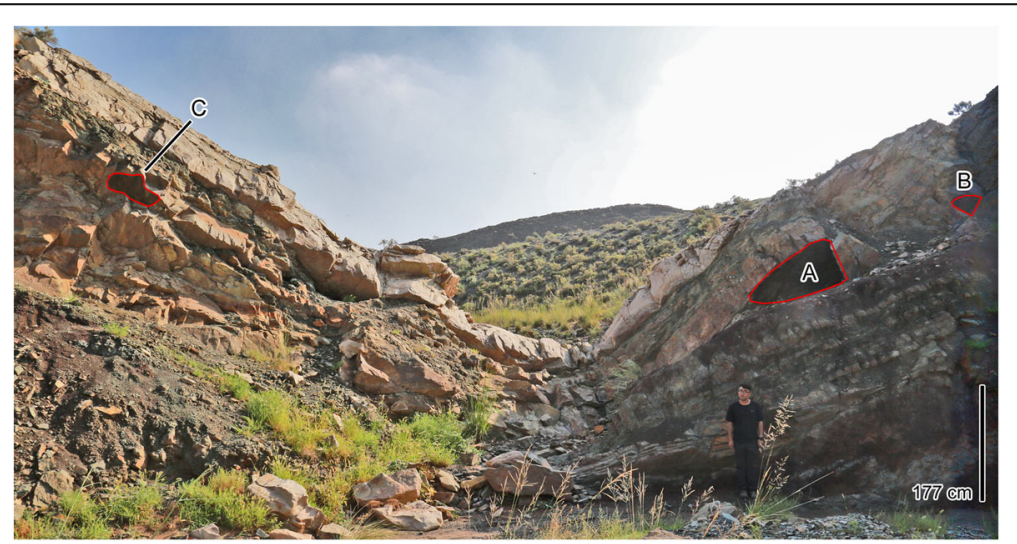

Fig. 3 Field photo of the track-bearing outcrops from which Pingchuan assemblages A-C were recorded. Compared with Figs. 4, 5, 6 and 7 in detail below 


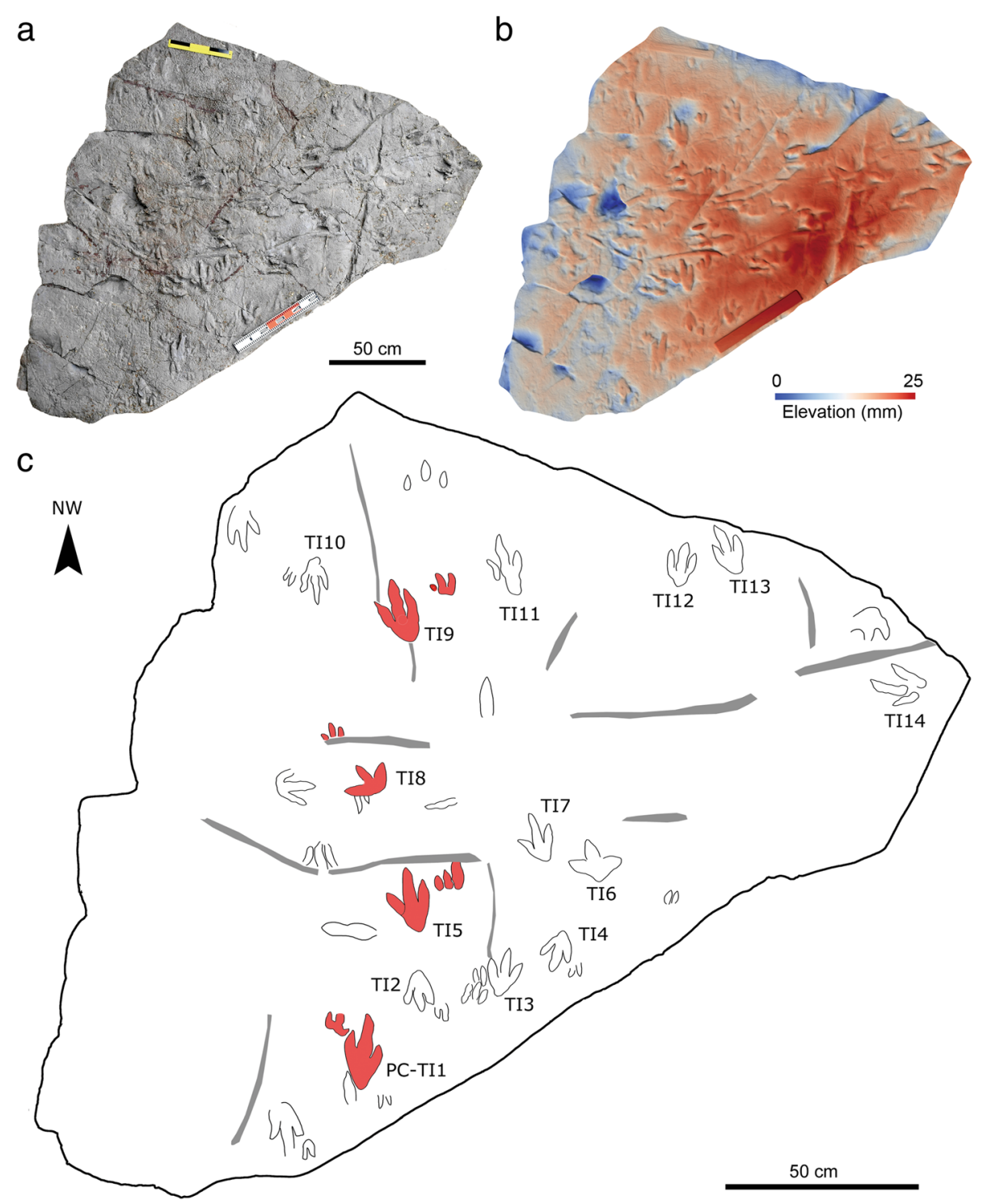

Fig. 4 Field photo (a), 3D image (b) and interpretative outline drawing (c) of theropod tracks at Pingchuan assemblage A

In addition to pes tracks Type $\mathrm{A}$ and Type $\mathrm{B}$ of the assemblage A (Type B most likely representing extramorphological variants of Type A), other tracks can be inferred to represent manus tracks. These have ichnotaxonomic significance, but are not given numerical or alphabetic labels, because we consider them to be associated with four tracks (PC-TI1, PC-TI5, PC-TI8 and PC-TI9) in the Type A group.

Assemblage $\mathrm{B}$ has at least 4 tracks oriented to the northwest, among which PC-TI15 is in the best preservation condition and in similar morphology to PC-TI3.

Assemblage $\mathrm{C}$ has at least 12 tracks, among which PC-TI16-PC-TI18 are better preserved. All of them lack metatarsophalangeal pad trace, so they only preserve traces of the main, distal part of digits II-IV. The lengths of PC-TI16-PC-TI18 are between $6.2 \mathrm{~cm}$ and $>8.8 \mathrm{~cm}$ (Table 1), measured from the traces of digit III, which are the deepest. The traces of digit II and IV are significantly shorter and much shallower (cf. Avanzini 1998). Some of the better preserved tracks, such as PC-TI16, show two observable digit pad traces associated with digit III. These tracks are frequently overlapped and both PC-TI17 and PC-TI18 overlap on another tridactyl track. All tracks point to northwest.

\section{Ichnotaxonomic implications}

5.1 Defining trackways

Due to the small size of the three outcrop areas, it is difficult to discern trackways, especially when so many tracks have the same orientation. However, it appears 


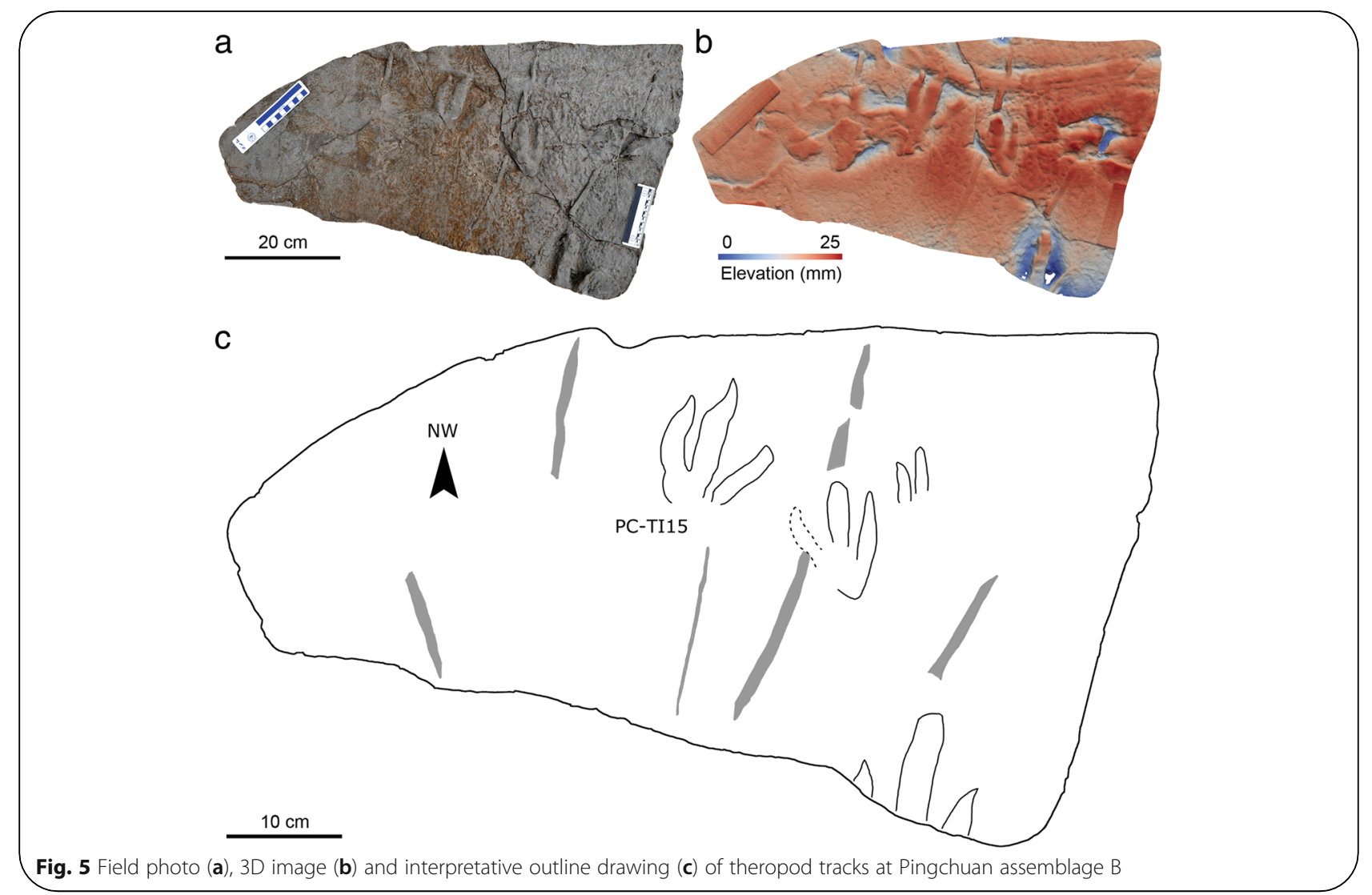

that tracks PC-TI1, PC-TI5, PC-TI8 and PC-TI9 from the Pingchuan assemblage A can constitute a trackway (Fig. 4). These tracks are separated by three similar pace lengths $(44 \mathrm{~cm}, 37 \mathrm{~cm}$ and $39 \mathrm{~cm})$. As is clearly seen in Fig. 4, pes tracks PC-TI1, PC-TI5, and PC-TI9 are very similar in size with mean length of $17.9 \mathrm{~cm}$, and are also the three largest tracks in the assemblage A. This, as well as their parallel alignment supports their being part of the same trackway. Track PC-TI8 registered only the distal portion of the pes, thus suggesting a momentary digitigrade touchdown. This is likely a function of differential preservation, especially in the case of this trackway which, as noted below is quite regular in configuration. More significantly, each pes track appears to have an associated manus impression situated lateral to pes digit IV traces. This means the left-right sequence corresponding to tracks PC-TI1, PC-TI5, PC-TI8 and PC-TI9 is L-R-L-R. Moreover, the presumed manus tracks appear to have the longest outer digit (III), which is exactly as reported for inferred theropod manus tracks described by Gierliński (1994).

We infer that the aforementioned sequence (PC-TI1, PC-TI5, PC-TI8 and PC-TI9) must be a trackway. It exhibits a short series of steps (mean length of $40.0 \mathrm{~cm}$ ), which is as $2.23 \times$ long as the mean footprint length, suggesting a slow speed. Examples of theropod tracks with manus traces are rare and almost exclusively associated with the Early Jurassic tracksites where theropods were crouching (Gierliński 1994; Gierliński et al. 2009; Milner et al. 2009). In these cases the theropod manus tracks were tridactyl and comparable to those described here. Clearly crouching trace involves a reduction in speed, and momentary or prolonged periods without forward progression. Known crouching traces are associated with no more than two manus tracks (Gierliński 1994; Gierliński et al. 2009; Milner et al. 2009). Thus, we inferred that no example of theropod manus tracks was found in association with a normal, walking trackway rather than a crouching posture. For this reason we proposed that the crouching trace represents a mode of theropod locomotion not reported previously and that the morphological configuration of the trackway has not previously been described. We are therefore justified in naming the new ichnotaxon Grallator pingchuanensis isp. nov.

\subsection{Systematics \\ Theropoda}

\section{Ichnogenus Grallator}

Ichnospecies Grallator pingchuanensis isp. nov. (Figs. 4, 7, 8 and 9).

Diagnosis: Grallatorid trackway showed elongate tridactyl mesaxonic Grallator-like pes with high pace angulation values. Manus tracks were tridactyl, ectaxonic short and 


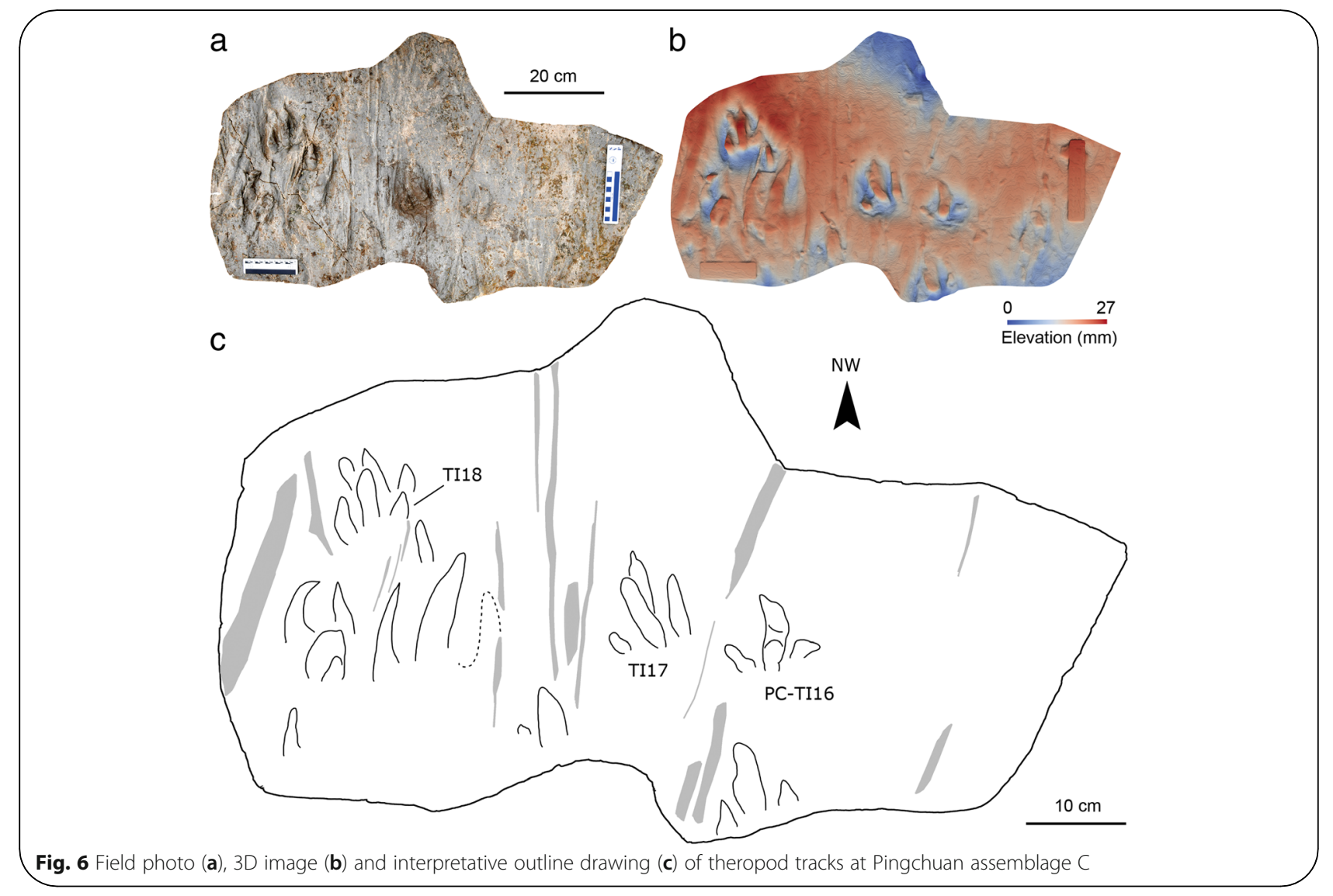

wide, situated antero-lateral to pes tracks with lower pace angulation values than pes.

Holotype: Trackway was composed of four pes tracks and four manus tracks (PC-TI1, PC-TI5, PC-TI8, PC-TI9 series, and associated manus tracks) from the surface A. The resin cast replica of holotype was numbered IVPG-F001.

Type horizon and locality: Wangjiashan Formation, Middle Jurassic, Pingchuan tracksite, Gansu Province, Northwest China.

Description: Pes tracks, tridactyl, mesaxonic (III > II=IV), elongate (twice as long as wide): mean length $(\mathrm{L})=17.9 \mathrm{~cm}$, mean width $(\mathrm{W})=8.9 \mathrm{~cm}$, and mean $\mathrm{L} / \mathrm{W}$ ratio $=2.01$ for tracks PC-TI1, PC-TI8 and PC-TI9, showing consistent inward rotation of $10^{\circ}$. Manus tracks, tridactyl, ectaxonic (III $>$ II $>$ I), slightly transverse (width was generally wider than length): length $=5.0-6.0 \mathrm{~cm}$, width $=\sim 6.0-7.0 \mathrm{~cm}$, mean length $=5.5 \mathrm{~cm}$, mean width $=\sim 6.5 \mathrm{~cm}$, and mean $\mathrm{L} / \mathrm{W}$ ratio $=0.85$. Manus tracks were with slight inward rotation. Pes trackway: width $=\sim 18.4 \mathrm{~cm}$, pace anglulation $=$ $140^{\circ}-150^{\circ}$. Manus trackway: width $=36.7 \mathrm{~cm}$, pace anglulation $=104^{\circ}-106^{\circ}$. Pes and manus steps were
$40 \mathrm{~cm}$ and $49 \mathrm{~cm}$ respectively on average; and, pes and manus strides were respectively $70 \mathrm{~cm}$ and $76 \mathrm{~cm}$ on average.

\subsection{Systematic discussion}

The most notable features of the trackway configuration are that the elongate tricdactyl pes is consistently associated with a slightly transverse ectaxonic manus, with the largest digit III (III > II > I). These are exactly the proportions described by Gierliński (1994) for Grallator tuberosus from the Lower Jurassic Portland Formation in Connecticut (AC 1/1, in the famous Hitchcock collections at Amherst College). It is interesting that the manus and pes tracks in this specimen, based on natural impressions of concave epireleifs, are very similar in size (mean length of $17.7 \mathrm{~cm}$ ); but the manus length $(4.6 \mathrm{~cm})$ seems to be less than the width in the published map (Gierliński 1994, his Fig. 3). Measurements obtained from this figure showed that the manus L/W ratio is same also about 0.80 , as the ratio got from the Pingchuan specimen. Milner et al. (2009) reported manus traces with "medially directed digits" associated with theropod crouching and much larger pes tracks (mean length of $41.1 \mathrm{~cm}$ ), from the Lower Jurassic Moenave Formation in Utah. The size of the manus tracks was not given precisely but is here 

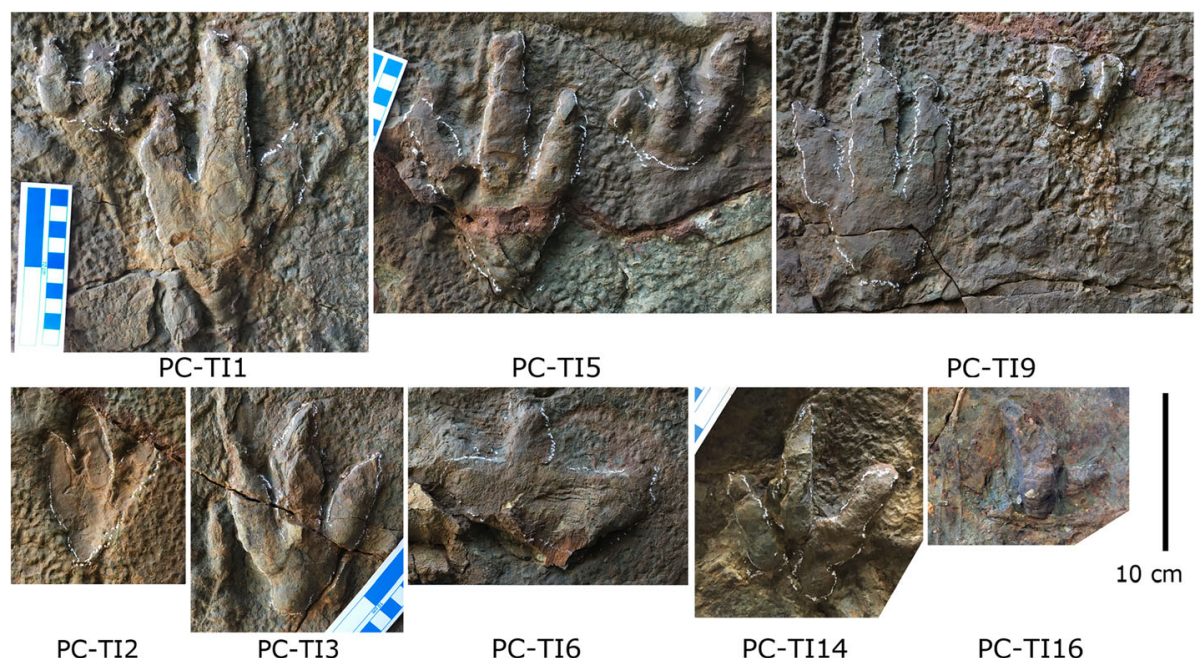

PC-TI9

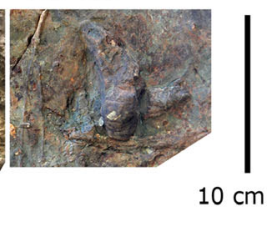

PC-TI14

PC-TI16

Fig. 7 Details of various tracks in the series PC-TI1-PC-TI3, PC-TI5-PC-TI6, PC-TI9, PC-TI14, and PC-TI16

measured as $4.0 \mathrm{~cm}$ long and $5.5 \mathrm{~cm}$ wide by authors, based on published illustrations $(\mathrm{L} / \mathrm{W}$ ratio $=0.80$ ). In the case of the crouching theropod tracks from the Lower Jurassic Drzewica Formation, Gierliński et al. (2009, p. 472) described as "the manus tracks are much smaller than the pes and slightly wider $(5.0 \mathrm{~cm})$ than long $(4.5 \mathrm{~cm})$ ". The associated pes tracks are $23 \mathrm{~cm}$ long, and the left manus track is slightly antero-lateral to the pes digit III whereas the right manus track is clearly tridactyl and situated slightly antero-medial to pes digit III. The track type (ichnotaxon) was not identified definitively but described only as "similar to... Eubrontes .... and Anchisauripus", which are types of the Grallator-Anchisauripus-Eubrontes plexus (Olsen et al. 1998; and references therein).

McCrea et al. (2014) referred to and illustrated the trackway of a large Cretaceous theropod, whose pes length was about $50 \mathrm{~cm}$ and with a pair of elongate tridactyl scrape marks up to $100 \mathrm{~cm}$ long and $25 \mathrm{~cm}$ wide, registered with mirror image symmetry on either side of the trackway midline. Based on the pes tracks, the theropod appeared to be walking normally. Thus, it is not clear why these presumed manus traces were registered as elongate scrapes, rather than simple 'touch down' tracks. In brief, these traces are so different from the Middle Jurassic traces described here that there are few obvious similarities.

The Pingchuan trackway is the first report of a theropod trackway with four consecutive manus pes sets. The registration position of manus relative to pes is consistent throughout the trackway, with the manus registered antero-laterally to the pes which makes the manus step and stride longer and creates a much greater pace angulation value. This trackway configuration suggests that the trackmaker was also moving slowly with the presumably shorter arms adopting a straddle position. Using the formula of Alexander (1976), the estimation speed is 2.3 $\mathrm{km} / \mathrm{hr}$. $(0.64 \mathrm{~m} / \mathrm{s})$ based on the pedal impression stride lengths which indicate a trackmaker with a walking gait. It is interesting that the pes tracks of PC-TI1, PC-TI5 and PC-TI9 show consistent slight inward rotation of $10^{\circ}$. In this case, the inward rotation of pes tracks in theropod trackways is unusual and may be related to quadrupedal progression. The antero-medial manus position close to the pes, is similar in both Utah and Pingchuan examples. The Connecticut example has the manus in an antero-lateral position, more anteriorly relative to the pes.

\section{Discussion}

An interesting feature of the Pingchuan trackway is that tracks from three different levels all show similar orientation trends. The majority of mapped tracks (about 16 in number) from the largest assemblage A shows a northwest orientation with a lesser number $(\sim 11)$ oriented exactly to the opposite southeast direction. Meanwhile, in assemblages B and C all tracks are oriented to the northwest. This suggests there could have been some physical paleoenvironmental constraints, for example a convenient linear drainage that persisted for the duration represented by the deposition of the $90 \mathrm{~cm}$ sediment between levels A and C. A second alternative interpretation would be that theropod dinosaurs were moving as gregarious groups, in the same direction on three separate occasions (cf., Ostrom 1972). The third alternative explanation is that both above factors influence the trackmakers' directions: groups of gregarious theropods moved in a landscape with physical feataures which encouraged movement in a preferred direction.

An important difference between tracks from the larger assemblage $\mathrm{A}$ and the smaller assemblage $\mathrm{C}$ is that the tracks from the smaller assemblage are much shorter and apparently digitigrade. Thus the difference in 


\section{Pes trackway width<smiles>[CH][IH]C</smiles>

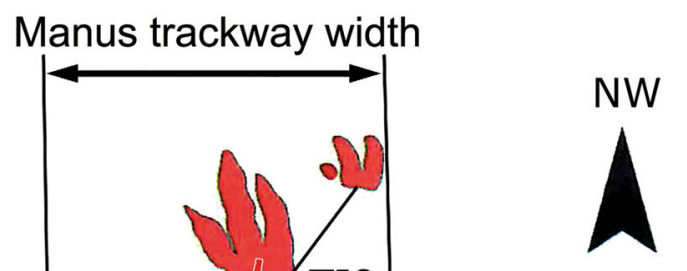

$50 \mathrm{~cm}$

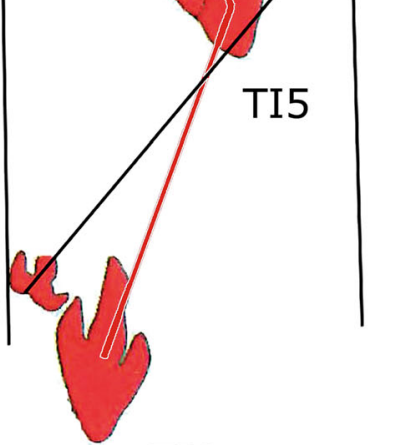

TI1

Fig. 8 Type trackway of Grallator pingchuan ichnosp. nov., showing details of trackway configuration

average length is $13.58 \mathrm{~cm}$ compared with $7.77 \mathrm{~cm}$ for assemblages $\mathrm{A}$ and $\mathrm{C}$, whereas the width difference is only between $8.76 \mathrm{~cm}$ and $7.36 \mathrm{~cm}$. This clearly indicates that the tracks in assemblage $\mathrm{C}$ appear more digitigrade, due to preservational or behavioral factors. We have also noted that digit III traces are deeper in assemblage C. This is a same pattern reported by Avanzini (1998) in analysis of the preservation of theropod tracks of $17.0 \mathrm{~cm}$ long, almost exactly the same length as tracks in the Pingchuan assemblages.

The Pingchuan theropod tracks can clearly be referred to as grallatorid in the broader sense of the Grallator-Eubrontes plexus (Lockley et al. 2013), and are here assigned to a new ichnospecies (G. pingchuanensis) of the former ichnogenus on the basis of a unique and diagnostic trackway pattern with novel implications for theropod behavior. All four known examples, in order of reporting (Connecticut, Poland, Utah and Gansu), are from the Lower-Middle Jurassic, and all represent Grallator or a closely related ichnogenus. This raises questions as to whether crouching theropod Grallator, or Grallator-like trackmakers engaged in gaits and postures that allowed registration of manus tracks. Since no trackway of a quadrupedal theropod has previously been reported, it is not known if the short step and inward rotation of the pes is a necessary corollary of the wide spacing of the manus traces 


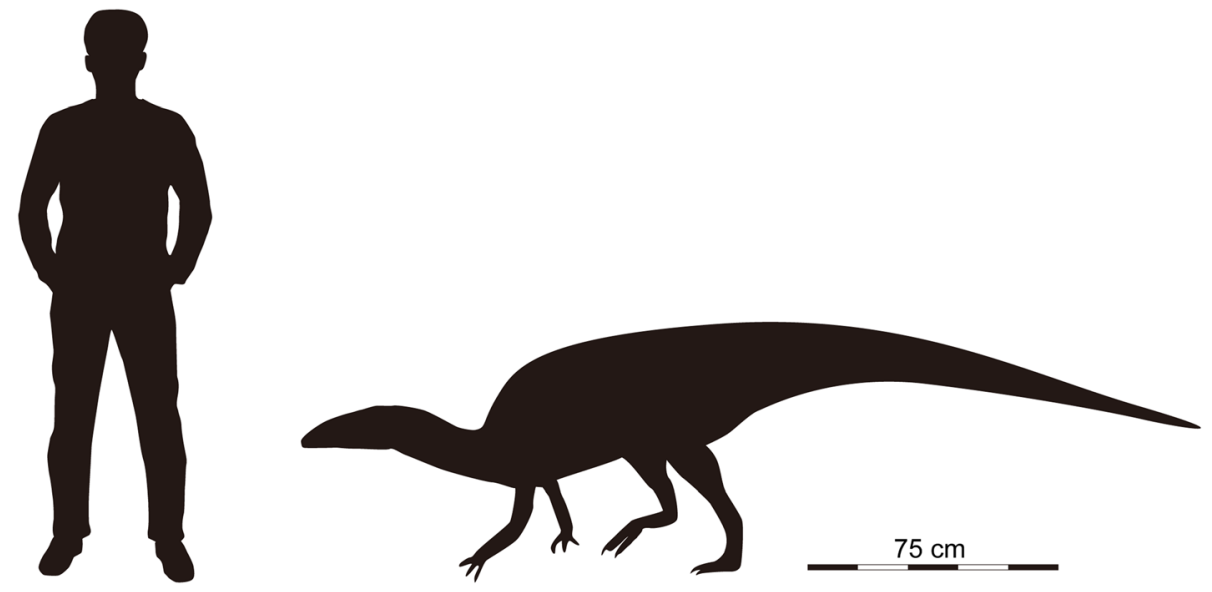

Fig. 9 Size of the possible trackmaker of Grallator pingchuan ichnosp. nov. compared with a human

and their positions relative to the pes. A functional locomotor/biomechanical analysis of potential trackmakers based on the known Lower Jurassic theropod skeletal reconstructions is outside the scope of this paper but could shed light on these questions.

It is well known that Grallator and Grallator-like tracks were widely distributed globally during the Early-Middle Jurassic. For example, Lucas (2007) considered the theropod tracks Grallator and Eubrontes (and Kayentapus) as indicative of the Early Jurassic biochron (cf. Lockley et al. 2013). Xing et al. (2013b, 2013c) described the medium-sized theropod tracks from the Middle Jurassic of Southwest China as Chongqingpus in Nan'an and Jinji tracksites in Chongqing region (Xing et al. 2013b) and as Kayentapus in Panxi region (Xing et al. 2013c). The latter assemblages are heavily theropod-dominated. Thus, the Pingchuan assemblages are similar to others of the Early-Middle Jurassic theropod track assemblages in China (Lockley et al. 2013).

\section{Conclusions}

The Pingchuan theropod tracksite in Gansu, Northewest China provides the fourth example (reporting after examples successively from Connecticut, Poland, Utah) of a theropod trackway with convincing examples of ectaxonic, tridactyl manus tracks, in this case forming a configuration of four consecutive manus pes sets. This example contrasts with others where only two tracks were recorded in association with traces indicating crouching behavior. All examples to date are the Early or Middle Jurassic in age. This unique example of a trackway of a theropod progressing quadrupedally is designated as Grallator pingchuanensis ichnosp. nov. Among the trackways, unique features are the evidence showing that the trackmaker's forelimbs register a wide straddle gait. The trackmaker was walking slowly which made deep tracks over a soft substrate. This is the first evidence that theropods occasionally registered manus traces while moving, rather than only when crouching.

\section{Abbreviations}

AC: Hitchcock collections at Amherst College, USA; IVPG: Institute of Vertebrate Paleontology, Gansu Agricultural University, China; PC: Pingchuan tracksite, Gansu Province, China

\section{Acknowledgements}

The authors are grateful to Jerry Harris for his constructive reviews that improved the manuscript largely. And, we thank Profs. Xiao-Qiao Wan, Hai-Lu You and an anonymous reviewer for their critical comments and suggestions on this paper. We also thank the Dinosaur Trackers Research Group, University of Colorado Denver, for the kind support.

\section{Funding}

This study was supported by the Scientific Innovative Funds and Special Funds for Discipline Construction of Gansu Agricultural University (Grant Nos. 066056001 and GAU-XKJS-2018-159), the National Natural Science Foundation of China (Grant Nos. 41790455 and 41772008), the Fundamental Research Funds for the Central Universities (Grant No. 2652017215), and the State Key Laboratory of Palaeobiology and Stratigraphy (Nanjing Institute of Geology and Palaeontology, Chinese Academy of Sciences) (Grant No. 173127).

Availability of data and materials

All data generated or analysed during this study are included in this published article.

\section{Authors' contributions}

Conceived and designed the experiments: D-QL, L-DX. Performed the experiments: D-QL, L-DX, MGL, AR, J-TY, L-FL. Analyzed the data: L-DX, MGL, AR. Contributed reagents/materials/analysis tools: D-QL, L-DX, J-TY, L-FL. Wrote the paper: L-DX, MGL, AR. All authors read and approved the final manuscript.

\section{Competing interests}

The authors declare that they have no competing interests.

\section{Publisher's Note}

Springer Nature remains neutral with regard to jurisdictional claims in published maps and institutional affiliations.

\section{Author details}

'Institute of Vertebrate Paleontology and College of Life Science and Technology, Gansu Agricultural University, Lanzhou 730070, Gansu Province, China. ${ }^{2}$ School of Earth Sciences and Resources, China University of Geosciences (Beijing), Beijing 100083, China. ${ }^{3}$ State Key Laboratory of Biogeology and Environmental Geology, China University of Geosciences 
(Beijing), Beijing 100083, China. ${ }^{4}$ Dinosaur Trackers Research Group, University of Colorado Denver, PO Box 173364, Denver, CO 80217, USA. ${ }^{5}$ School of Biological Sciences, The University of Queensland, Brisbane, Queensland 4072, Australia.

\section{Received: 2 October 2018 Accepted: 30 January 2019}

\section{Published online: 26 February 2019}

\section{References}

Ahrens, J., B. Geveci, and C. Law. 2005. ParaView: an end-user tool for large data visualization. Visualization handbook, Elsevier, 717-732.

Alexander, R. 1976. Estimates of speeds of dinosaurs. Nature 261: 129-130.

Avanzini, M. 1998. Anatomy of a footprint: Bioturbation as a key to understanding dinosaur walk dynamics. Ichnos 6: 129-139.

Bohlin, B. 1953. The Sino-Swedish expedition publication 37, VI. Vertebrate Palaeontology 6: Fossil Reptiles from Mongolia and Kansu, 113. Stockholm: Statens Etnografiska Museumin.

Deng, S.H., Y.Z. Lu, Y. Zhao, R. Fan, Y.D. Wang, X.J. Yang, X. Li, and B.N. Sun. 2017 The Jurassic palaeoclimate regionalization and evolution of China. Earth Science Frontiers 24 (1): 106-142 (in Chinese with English Abstract).

Du, B.-A. 1985. Sporo-pollen assemblages from the middle Jurassic in the Wangjiashan Basin of Jingyuan, Gansu, and their stratigraphic and paleogeographic significance. Geological Review 31 (2): 131-141 (in Chinese with English Abstract).

Gierliński, G.D. 1994. Earky Jurassic theroipod tracks with the metatarsal impressions. Prezglad Geologiczny 42: 280-284.

Gierliński, G.D., M.G. Lockley, and G. Niedźwiedzki. 2009. A distinctive crouching theropod trace from the lower Jurassic of Poland. Geological Quarterly 53: $471-475$

Lallensack, J.N. 2018. Automatic generation of objective footprint outlines, Chapter 4, 105-114. Bonn: Doctoral Thesis.

Li, B.X., F.X. Xu, Q.H. Ma, H.Z. Pan, S.Q. Wang, and Z.W. Li. 1982. Middle Jurassic strata of Wangjiashan Basin, Jingyuan, Gansu. Journal of Stratigraphy 6 (1): 33-40 (in Chinese with English Abstract).

Li, D.Q., L.D. Xing, M.G. Lockley, L. Piñuela, J.P. Zhang, H. Dai, J.Y. Kim, W.S.IV. Persons, and D.L. Kong. 2015. A manus dominated pterosaur track assemblage from Gansu, China: Implications for behavior. Science Bulletin 60 (2): 264-272

Li, K., J. Liu, C. Yang, and F. Hu. 2011. Dinosaur assemblages from the middle Jurassic Shaximiao formation and Chuanjie formation in the Sichuan-Yunnan Basin, China. Volumina Jurassica 9: 21-42.

Lockley, M.G. 2009. New perspectives on morphological variation in tridactyl footprints: Clues to widespread convergence in developmental dynamics. Geological Quarterly 53: 415-432.

Lockley, M.G., J. Li, R. Li, M. Matsukawa, J.D. Harris, and L.D. Xing. 2013. A review of the tetrapod track record in China, with special reference to type ichnospecies: Implications for ichnotaxonomy and paleobiology. Acta Geologica Sinica 87: 1-20.

Lucas, S.G. 2007. Tetrapod footprint biostratigraphy and biochronology. Ichnos 14 : $5-38$.

McCrea, R.T., L.G. Buckley, A.G. Plint, P.J. Currie, J.W. Haggart, C.W. Helm, and S.G. Pemberton. 2014. A review of vertebrate track-bearing formations from the Mesozoic and earliest Cenozoic of western Canada with a description of a new theropod ichnospecies and reassignment of an avian ichnogenus. New Mexico Museum of Natural History \& Science Bulletin 62: 50-93.

Milner, A.R.C., J.D. Harris, M.G. Lockley, J.L. Kirkland, and N.A. Matthews. 2009. Birdlike anatomy, posture, and behavior revealed by an early Jurassic theropod dinosaur resting trace. Plos One 4 (3): e4591.

Olsen, P.E. 1980. Fossil great lakes of the Newark Supergroup in New Jersey. In Field Studies of New Jersey Geology and Guide to Field Trips, New York State Geology Association 52 ${ }^{\text {nd }}$ Annual Meeting, Rutgers University, ed. W. Manspeizer, 352-298

Olsen, P.E., J.B. Smith, and N.G. McDonald. 1998. The material of the species of the classic theropod footprint genera Eubrontes, Anchisauripus and Grallator (early Jurassic, hart ford and Deerfield basins, Connecticut and Massachusetts, USA). Journal of Vertebrate Paleontology 18 (3): 586-601.

Ostrom, J. 1972. Were some dinosaurs gregarious? Palaeogeography Palaeoclimatology Palaeecology 11: 287-301.

Weems, E. 1992. Re-evaluation of the taxonomy of Newark Supergroup saurischian dinosaur tracks, using extensive statistical data from a recently exposed tracksite near Culpeper, Virginia. In Proceedings of $26^{\text {th }}$ forum on the geology of industrial minerals. Virginia division of mineral resources publication Charlottesville, ed. P.C. Sweet, vol. 119, 113-127.

Xing, L.D., L.G. Buckley, M.G. Lockley, J.P. Zhang, D. Marty, Y. Wang, J.J. Li, R.T. McCrea, and C. Peng. 2016a. A new bird track, Koreanaornis lii ichnosp. nov., from the lower cretaceous Hekou Group in the Lanzhou-Minhe Basin, Gansu, Northwest China, and implications for early cretaceous avian diversity. Cretaceous Research 66: 141-154.

Xing, L.D., D.Q. Li, P.L. Falkingham, M.G. Lockley, M.J. Benton, H. Klein, J.P. Zhang H. Ran, W.S.I.V. Persons, and H. Dai. 2016b. Digit-only sauropod pes trackways from China - Evidence of swimming or a preservational phenomenon? Scientific Reports 6: 21138

Xing, L.D., D.Q. Li, J.D. Harris, P.R. Bell, Y. Azuma, M. Fujita, Y. Lee, and P.J. Currie. 2013a. A new deinonychosaurian track from the lower cretaceous Hekou group, Gansu Province, China. Acta Palaeontologica Polonica 58 (4): 723-730.

Xing, L.D., D.Q. Li, M.G. Lockley, D. Marty, J.P. Zhang, W.S.I.V. Persons, H.L. You, C. Peng, and S.B. Kümmell. 2015. Dinosaur natural track casts from the lower cretaceous Hekou Group in the Lanzhou-Minhe Basin, Gansu, Northwest China: Ichnology track formation, and distribution. Cretaceous Research 52: 194-205.

Xing, L.D., D.Q. Li, M.G. Lockley, J.P. Zhang, H.L. You, H. Klein, D. Marty, W.S.I.V. Persons, and C. Peng. 2014b. Theropod and sauropod track assemblages from the lower cretaceous Hekou Group at Zhongpu, Gansu Province, China. Acta Palaeontologica Sinica 53 (3): 381-391 (in Chinese with English Abstract).

Xing, L.D., M.G. Lockley, W. Chen, G.D. Gierliński, J. Li, W.S.I.V. Persons, M. Matsukawa, Y. Ye, M.K. Gingras, and C.W. Wang. 2013b. Two theropod track assemblages from the Jurassic of Chongqing, China, and the Jurassic stratigraphy of Sichuan Basin. Vertebrata Palasiatica 51: 107-130.

Xing, L.D., M.G. Lockley, Y. Guo, H. Klein, J.Q. Zhang, J. Zhang, W.S.I.V. Persons, A. Romilio, Y. Tang, and X. Wang. 2018. Multiple parallel deinonychosaurian trackways from a diverse dinosaur track assemblage of the lower cretaceous Dasheng Group of Shandong Province, China. Cretaceous Research 90: 40-55.

Xing, L.D., M.G. Lockley, Z.D. Li, H. Klein, J. Zhang, G. Gierliński, Y. Ye, W.S.I.V. Persons, and L. Zhou. 2013c. Middle Jurassic theropod trackways from the Panxi region, Southwest China and a consideration of their geologic age. Paleoworld 22: 36-41.

Xing, L.D., D. Marty, H.L. You, D.Q. Li, H. Klein, D. Knaust, J.P. Zhang, R.T. McCrea, and W.S.I.V. Persons. 2017. Complex in substrate dinosaur (Sauropoda, Ornithopoda) foot pathways revealed by deep natural track casts from the lower cretaceous Xiagou and Zhonggou formations, Gansu Province, China. Ichnos 24 (3): 163-178.

Xing, L.D., G. Niedźwiedzki, M.G. Lockley, J.P. Zhang, X.F. Cai, W.S.I.V. Persons, and Y. Ye. 2014a. Asianopodus type footprints from the Hekou Group of Honggu District, Lanzhou City, Gansu, China and the "heel" of large theropod tracks. Palaeoworld 23: 304-313.

Young, C.C. 1948. Fossil crocodiles in China, with notes on dinosaurian remains associated with the Kansu crocodiles. Bulletin of the Geological Society of China 28 (3-4): 255-288 (in Chinese with English Abstract).

Young, C.C. and X.J. Zhao. 1972. Mamenchisaurus hochuanensis sp. nov. Institute of Vertebrate Paleontology and Paleoanthropology Monographs, Serie A. Vol. 8, 1-30.

Zhang, H. 2009. Sedimentary environments and coal accumulation of the Baojishan-Honghui Basin, eastern Qilian Mountains. Acta Sedimentologica Sinica 27 (4): 622-631 (in Chinese with English Abstract).

Zhang, J.P., D.Q. Li, M.L. Li, M.G. Lockley, and Z. Bai. 2006. Diverse dinosaurpterosaur-, and bird-track assemblages from the Hakou formation, lower cretaceous of Gansu Province, Northwest China. Cretaceous Research 27: 44-55. 